\title{
Study of interactions between antigens and polymeric adjuvants in vaccines by frontal analysis continuous capillary electrophoresis
}

\author{
Camille Malburet $^{1,2}$, Laurent Leclercq ${ }^{1}$, Jean-François Cotte ${ }^{2}$, Jérôme Thiebaud ${ }^{2}$, Hervé Cottet $^{1 *}$ \\ ${ }^{1}$ IBMM, University of Montpellier, CNRS, ENSCM, Montpellier, France \\ 2 Sanofi Pasteur, Analytical Sciences, 1541 avenue Marcel Mérieux, 69280, Marcy l'Etoile, France. \\ *Corresponding author: herve.cottet@umontpellier.fr
}

\begin{abstract}
Vaccine adjuvants are used to enhance the immune response induced by antigens that have insufficient immunostimulatory capabilities. The present work aims at developing frontal analysis continuous capillary electrophoresis (FACCE) methodology for the study of antigenadjuvant interactions in vaccine products. After method optimization using three cationic model proteins, namely lysozyme, cytochrome $\mathrm{C}$ and ribonuclease A, FACCE was successfully implemented to quantify the free antigen and thus to determine the interaction parameters (stoichiometry and binding constant) between an anionic polymeric adjuvant (polyacrylic acid, SPA09), and a cationic vaccine antigen in development for the treatment of Staphylococcus aureus. The influence of the ionic strength of the medium on the interactions was investigated. A strong dependence of the binding parameters with the ionic strength was observed. The concentration of the polymeric adjuvant was also found to significantly modify the ionic strength of the formulation, the extent of which could be estimated and corrected.
\end{abstract}

Key Words: Frontal analysis continuous capillary electrophoresis, interactions, polymeric adjuvant, vaccines 


\section{Introduction}

Vaccination combined with clean water access, improved hygiene practices and antibiotics allowed to drastically reduce mortality from infectious diseases during the last century ${ }^{1}$. A report from the World Health Organization states that vaccines saves up to 2-3 million lives per year ${ }^{2}$. In addition to preventing deaths, vaccines also massively reduce diseases and disabilities.

Despite huge advancement in vaccine development, many challenges remain, and the list of unmet medical needs is still long ${ }^{3}$. Moreover, epidemics caused by viral infections are emerging almost every year. Those outbreaks, characterized by their unpredictability, high morbidity, exponential spread, and significant social impact require a rapid development of new vaccines ${ }^{4,5}$. In addition, the increasing spread of antibiotic resistance in bacterial pathogens is also a growing threat to public health ${ }^{6,7}$. Thus, vaccines against antibiotic-resistant bacteria are being developed $^{8,9}$. Furthermore, vaccines have today the potential to prevent or treat not only communicable diseases, but also diseases considered noncommunicable such as cancer and neurodegenerative disorders ${ }^{10-14}$. Put together, some 240 vaccine candidates are currently under development ${ }^{15}$.

Adjuvants have a key role to play in the new vaccine developments, they are used to enhance and modulate the immunogenicity of antigens that have insufficient immunostimulatory capabilities ${ }^{16,17}$. The strength of the antigen-adjuvant interaction has been shown to be able to increase or to decrease vaccines immunogenicity ${ }^{18-20}$. In that respect, Hansen B. et al. showed that the antibody production can be reduced when the antigen is too strongly adsorbed on the adjuvant $^{21-23}$. Thus, the development of new analytical methods to characterize the antigenadjuvant interactions is crucial to better understand the mode of action of adjuvants and their impact on the immunogenicity ${ }^{24,25}$. A better understanding of these interactions will allow to optimize vaccine efficacy and stability ${ }^{26}$. 
Among existing adjuvants, polymers including acrylic acid units have been used since the $1970 \mathrm{~s}^{27,28}$. Since then, many studies have confirmed the adjuvant activity of polyacrylic acid polymers and their derivatives ${ }^{29-33}$. Cross-linked polyacrylic acid polymers sold under the name Carbopol $\left(\right.$ are already used as effective adjuvants in several veterinary vaccines ${ }^{34-36}$. Polyacrylic acid polymers are also of great interest for the development of new human vaccines ${ }^{37-39}$. Indeed, the search for new vaccines antigens and more effective vaccines requires the search for new potent adjuvants $^{40,41}$. SPA09, a purified linear polyacrylic acid polymer, has in particular been identified as a new promising human adjuvant ${ }^{42,43}$.

Some analytical techniques are already commonly used to study antigen-adjuvant interactions: Isothermal Titration Calorimetry (ITC) is based on the measurement of the heat released or absorbed during a binding event between two entities ITC gives access to the enthalpy changes $(\Delta H)$, the entropy change $(\Delta S)$, the binding site constant $(k)$ and the interaction stoichiometry $(n)^{44-46}$. Differential Scanning Calorimetry (DSC) gives access to the melting temperature $\left(T_{m}\right)$ by measuring the heat variation associated with the thermal denaturation of a molecule or a complex when it is subjected to a temperature ramp. Thus, DSC can give information on the presence or absence of interaction as well as on the structure and stability of antigen-adjuvant complexes ${ }^{47,48}$. More recently, Surface Plasmon Resonance (SPR) and Bio Layer Interferometry (BLI) have become methods of great interest for interactions studies. SPR and BLI measure the changes in refractive index and the shift of the interference pattern, respectively, when a receptor binds to or separates from a ligand immobilized at the surface of a biosensor $^{49}$. SPR and BLI allows to access to the kinetic constants of association $\left(k_{\text {on }}\right)$ and dissociation $\left(k_{o f f}\right)$ and to the equilibrium dissociation constant $\left(K_{d}\right)$.

However, none of these methods gives direct access to the free ligand concentration, which is the parameter of choice to determine the isotherm of adsorption, and consequently, by curve 
fitting, the parameters of interaction (namely, the intrinsic binding constant and the stoichiometry of interaction).

Conversely, Frontal analysis continuous capillary electrophoresis (FACCE) is a straightforward technique allowing to quantify the free ligand concentration at equilibrium in a ligand/substrate mixture ${ }^{50}$. FACCE has been applied to many different systems such as oppositely charged polyelectrolytes ${ }^{51}$, small molecule-polyelectrolyte ${ }^{52-54}$, proteinpolyelectrolyte $\mathrm{e}^{55-60}$ or protein-drug ${ }^{61-67}$ binding. However, to our knowledge, this promising technique has never been used for the study of antigen-adjuvant interactions in vaccines. The principle of FACCE consists in applying a continuous voltage in the substrate-ligand equilibrated mixture, in order to selectively introduce in the capillary and to quantify the free ligand concentration. Generally, the analytical strategy is to limit as much as possible the entrance of the interacting complex in the capillary in order to: $(i)$ avoid any complex dissociation in the capillary; and (ii) avoid the occurrence of undesirable adsorption onto the capillary wall. Since the amount of free ligand which selectively enter in the capillary is very low compared to the total ligand amount contained in the inlet vial, the equilibrium is not perturbed. Among the main advantages of this technique which seems attractive for the study of antigen-adjuvant interactions, one can cite: $(i)$ the interaction study in conditions close to the conditions of formulation and/or biologically relevant; (ii) the possibility to wait for the equilibrium of the mixture before analysis; (iii) the relatively low volume/quantity of material required (nL injected, dozens of $\mu \mathrm{L}$ prepared per mixtures).

The present study aims at developing FACCE methodology under physiological conditions for the study of interactions between an anionic vaccine adjuvant SPA09 and a cationic vaccine antigen in development for the treatment of Staphylococcus aureus (PrSA). Staphylococcus 
aureus is a common human commensal organism which is a major cause of nosocomial infections worldwide. The method was first optimized using three cationic model proteins lysozyme, cytochrome c (Cyt C) and ribonuclease A (RNase A). From an analytical point of view, the challenge was to find the suitable experimental conditions allowing to avoid any interaction of the partners on the capillary wall during the FACCE analysis ensuring good reliability of the results. The final objective is to determine the binding parameters, i.e. the intrinsic binding constant $(k)$, the first successive binding constant $\left(K_{l}\right)$, and the stoichiometry of the antigen-adjuvant complex at saturation $(n)$. The influence of the ionic strength and the adjuvant concentration on the antigen-adjuvant interactions were also thoroughly investigated, since they are strongly related parameters which can be varied in the final vaccine formulation.

\section{Materials and methods}

\section{Chemicals}

$\mathrm{SPA}^{4} 9^{42}$ (polyacrylic acid, $M_{w}=590 \mathrm{kDa}, P D I=2.2$ ) was provided by Sanofi Pasteur (Marcy-l'Étoile, France) at $17.8 \mathrm{~g} / \mathrm{L}$ in phosphate-buffered saline buffer (PBS) (ionic strength 165 $\mathrm{mM}, \mathrm{pH}=7.4$ ). PrSA (peptidyl-prolyl cis-trans isomerase from Staphylococcus aureus, $M_{w}=35$ $\mathrm{kDa}, p I=9$ ) at $2.5 \mathrm{~g} / \mathrm{L}$ in tris(hydroxymethyl)aminomethane (TRIS) buffer (ionic strength 165 $\mathrm{mM}, \mathrm{pH}=7.4$ ) was provided by Sanofi-Pasteur (Marcy-l'Étoile, France). Lysozyme from chicken egg white $\left(M_{w}=14 \mathrm{kDa}, p I=11\right)$, Cyt C from bovine heart (cytochrome c, $M_{w}=12 \mathrm{kDa}$, $p I=10$ ), RNase A from bovine pancreas (ribonuclease A, $M_{w}=14 \mathrm{kDa}, p I=9$ ), TRIS $\left(\left(\mathrm{CH}_{2} \mathrm{OH}\right)_{3} \mathrm{CNH}_{2}, M_{w}=121 \mathrm{~g} / \mathrm{mol}\right)$ and polybrene $\left(\mathrm{PB}\right.$, hexadimethrine bromide, $\left.M_{w}=15 \mathrm{kDa}\right)$ were purchased from Merck (Darmstadt, Germany). PAA190 (polyacrylic acid, $M_{w}=190 \mathrm{kDa}$, $P D I=1.2)$ was purchased from Polymer Source. Inc. (Montreal, Canada). Deionized water was further purified with a Milli-Q system from Millipore (Molsheim, France). The SPA09 provided 
by Sanofi-Pasteur was dialyzed against Milli-Q water in order to eliminate the PBS buffer using Slide-A-Lyzer Dialysis Cassette G2 $3500 \mathrm{M}_{\mathrm{w}} \mathrm{CO}$ (ThermoFisher Scientific, Waltham, USA), and then freeze-dried. All the other chemicals were used without any further treatment.

\section{Sample preparation}

Stock solutions of SPA09, lysozyme, Cyt C and RNase A were prepared in TRIS buffer (80 $\mathrm{mM}$ TRIS, $68 \mathrm{mM} \mathrm{HCl}, 97 \mathrm{mM} \mathrm{NaCl}$ ) at $\mathrm{pH}$ 7.4. The stock solution concentration of SPA09 was set at $2 \mathrm{~g} / \mathrm{L}$, lysozyme at $1.6 \mathrm{~g} / \mathrm{L}, \mathrm{Cyt} \mathrm{C}$ and RNase A at $3.2 \mathrm{~g} / \mathrm{L}$. PrSA was already in solution in TRIS buffer at $2.5 \mathrm{~g} / \mathrm{L}$. All the stock solutions were subsequently diluted to the desired concentrations in TRIS buffer. These solutions were used for the calibration curves and for the preparation of the antigen-adjuvant mixtures. These mixtures were obtained by mixing $150 \mu \mathrm{L}$ of antigen solution and $150 \mu \mathrm{L}$ of adjuvant solution. Final solutions were homogenized by manual agitation before analysis by FACCE.

\section{FACCE}

In the case of lysozyme, Cyt $\mathrm{C}$ and RNase A, FACCE experiments were carried out on a 7100 CE Agilent system (Waldbronn, Germany). This system is equipped with a diode array detector. Bare fused silica capillaries were purchased from Polymicro Technologies (Phoenix, USA). Capillaries of $50 \mu \mathrm{m}$ i.d. $\times 33.5 \mathrm{~cm}$ total length $(8.5 \mathrm{~cm}$ to the detector $)$ were used. To reduce the migration times, the sample was introduced from the short-end $(8.5 \mathrm{~cm}$ to the detection point). The temperature of the capillary cartridge was set at $25^{\circ} \mathrm{C}$. The capillary was coated with polybrene using successive flushes of: $0.5 \%(\mathrm{w} / \mathrm{w})$ polybrene in water $(7 \mathrm{~min})$, Milli-Q water (1 min), and background electrolyte composed of $80 \mathrm{mM}$ TRIS buffer ( $1 \mathrm{~min})$. The capillary was flushed with a $0.5 \mathrm{M} \mathrm{NaOH}$ containing $2 \mathrm{M} \mathrm{NaCl}$ mixture to remove the polybrene coating from the capillary $(7 \mathrm{~min})$, and then coated again using the previous protocol between 
each analysis. FACCE experiments were performed by applying a voltage of $-7.5 \mathrm{kV}$ and a copressure of - 30 mbar (as stated in the chemstation software, i.e. from the long-end side of the capillary) to permit the entrance and the quantification of the (cationic) free protein, while avoiding the entrance of the negatively charged adjuvant and the protein-adjuvant complex. Free proteins were continuously and electrokinetically introduced into the capillary.

In the case of PrSA, FACCE experiments were carried out on a PA800 CE system from SCIEX (Framingham, USA). Bare fused silica capillaries were purchased from SCIEX (Framingham, USA). Capillaries of $50 \mu \mathrm{m}$ i.d. $\times 30 \mathrm{~cm}$ total length $(10 \mathrm{~cm}$ to the detector $)$ were used. Analyzes were performed on PB-coated capillaries using the same coating and rinsing procedures as described in the previous paragraph.

All FACCE experiments were performed in triplicates.

\section{Theoretical background}

\section{Isotherm of adsorption}

A straightforward way to study antigen-adjuvant interactions is to plot the isotherm of adsorption associated to these interactions ${ }^{68,69}$. In this study, the polymeric adjuvant SPA09 is considered as the substrate $(S)$ and the protein model or the vaccine antigen is considered as the ligand $(L)$. The isotherm of adsorption of the ligands onto the substrate is defined as the graphical representation of the average number of bound ligands per substrate $\bar{n}$ versus the free ligand concentration $[L] . \bar{n}$ can be obtained experimentally from the determination by FACCE of the free ligand concentration in different equilibrated ligand / substrate mixtures, according to equation (1):

$$
\bar{n}=\frac{[L]_{\text {bound }}}{[S]_{0}}=\frac{[L-S]}{[S]_{0}}=\frac{[L]_{0}-[L]}{[S]_{0}}
$$


where $[L]_{\text {bound }}$ is the concentration of bound ligand, $[S]_{0}$ is the initial substrate concentration introduced in the mixture and $[L]_{0}$ is the initial ligand concentration introduced in the mixture. The adjustment of the curve $\bar{n}=f([L])$ using a suitable mathematical model gives access to the desired binding parameters.

\section{Model of $\mathbf{n}$ independent sites of equal energy}

In the model of $n$ independent sites of equal energy, we assume that the substrate $(S)$ contains $n$ independent sites $(-s)$ of equal energy. The occupation of one site does not influence the occupation of the other sites. The interaction between one site $(-s)$ on the substrate and the ligand $(L)$ is described by the equilibrium (2):

$L+-S \stackrel{k}{\rightleftarrows} L-S$

The intrinsic binding site constant $k$ related to this equilibrium is defined by equation (3):

$k=\frac{[L-s]}{[-s][L]}$

where $[L-s]$ is the concentration of occupied sites, $[-s]$ is the concentration of free sites and $[L]$ is the concentration of free ligands. In the framework of this model, the isotherm of adsorption is described by the Langmuir model according to equation (4):

$\bar{n}=n \frac{k[L]}{1+k[L]}$

where $n$ and $k$ can be obtained by nonlinear curve fitting of the experimental isotherm of adsorption. When the entire isotherm can be obtained experimentally, the maximum number of interacting sites $n$ corresponds to the value of $\bar{n}$ at saturation of the isotherm. If, for any experimental reason, the saturating part of isotherm is not accessible, the slope at the origin of the 
isotherm can give access to the first successive binding constant $K_{l}=n \times k$ as demonstrated by the first derivative of equation (4):

$$
\lim _{[L] \rightarrow 0} \frac{d \bar{n}_{\text {具 }}}{d[L]}=\lim _{[L] \rightarrow 0} \frac{n k}{(1+k[L])^{2}}=n k=K_{1}
$$

The intrinsic binding constant $k$ should not be confused with the first successive binding constant $K_{1}$ defined as:

$$
S+L \stackrel{K_{1}}{\rightleftarrows} S L_{1}
$$

\section{Scatchard representation}

The model of $n$ independent sites of equal energy can be linearized for an easier determination of the binding parameters. The Scatchard representation is one method of linearization of the Langmuir adsorption isotherm which consists in plotting $\frac{\bar{n}}{[L]}$ as a function of

$\bar{n}$ according to equation (7):

$$
\frac{\bar{n}}{[L]}=n k-k \bar{n}
$$

The slope of the line gives access to the binding constant $k$, while the y-intercept estimates $K_{1}=n \times k$.

\section{Free ligand concentration}

Once the $\mathrm{n}$ and $\mathrm{k}$ parameters have been estimated/determined experimentally, it is then possible to calculate the free ligand concentration for any ligand-substrate mixing ratio, according to equation (8):

$[L]=\frac{-\left(n k[S]_{0}-k[L]_{0}+1\right)+\sqrt{\left(1-k[L]_{0}+n k[S]_{0}\right)^{2}+4 k[L]_{0}}}{2 k}$ 


\section{Ionic strength dependence of the binding constant}

Taking into account the release of the counter-ions associated with the first successive equilibrium, the chemical equilibrium (6) can be written as (9):

$$
S_{N_{N a^{+}}}+L_{N_{C l^{-}}} \stackrel{K_{1}^{0}}{\rightleftarrows} S L+\left(\chi^{+} N_{N^{+}}\right) N a^{+}+\left(\chi^{-} N_{C l^{-}}\right) C l^{-}
$$

where $K_{1}^{0}$ is the first interaction constant of the equilibrium which takes into account the release of counter-ions. $N_{\mathrm{Na}+}$ and $N_{\mathrm{Cl}}{ }^{-}$are the number of counter-ions condensed onto the substrate and the ligand, respectively, before association. $\chi^{+}$and $\chi^{-}$are the fractions of the counter-ions $\mathrm{Na}^{+}$and $\mathrm{Cl}^{-}$released after the association.

The relationship between $K_{1}$ and $K_{1}^{0}$ is given by equation $(10)^{51}$ :

$K_{1}^{0}=K_{1} \times\left[\mathrm{Na}^{+}\right]^{\chi^{+} N_{\mathrm{Na}^{+}}} \times\left[\mathrm{Cl}^{-}\right]^{\chi^{-} N_{\mathrm{Cl}^{-}}}$

which can be rewritten as equation (11):

$\log K_{1}=\log K_{1}^{0}-\left(\chi^{+} N_{N a^{+}}+\chi^{-} N_{c^{-}}\right) \log ([I])$

where $I$ represents the ionic strength of the medium, assuming that $\left[\mathrm{Na}^{+}\right]=\left[\mathrm{Cl}^{-}\right]=[\mathrm{I}$.

Equation (11) shows that a linear dependency is expected between the logarithm of the first successive interaction constant $K_{l}$ and the logarithm of the ionic strength [I]. The slope of this linear dependence represents the number of the counter-ions that are released from the association of one ligand with the substrate. 


\section{Results and Discussion}

\section{Development and optimization of the FACCE methodology}

Before studying interactions between vaccine antigens and SPA09 adjuvant, three model proteins were used to develop the FACCE method, namely, lysozyme, Cyt C and RNase A. These proteins are positively charged at $\mathrm{pH} 7.4$ (see Table 1), and thus were supposed to interact, at least electrostatically, with the polymeric adjuvant which is negatively charged at $\mathrm{pH} 7.4$. As the adjuvant charge density is much higher than the charge density of the proteins, the proteinadjuvant complexes are supposed to be negatively charged ${ }^{70}$.

Table 1. Isoelectric point $(p I)$, molar mass $(M)$, weight-average hydrodynamic radius $\left(R_{h}\right)$ and effective electrophoretic mobility $\left(\mu_{e p}\right)$ of the studied model proteins and vaccine antigens. Experimental conditions for $R_{h}$ data (Taylor Dispersion Analysis): HPC-coated capillary of $58.5 \mathrm{~cm}$ total length $(50 \mathrm{~cm}$ to the detector $) \times 100 \mu \mathrm{m}$ i.d. Buffer: $20 \mathrm{mM}$ TRIS-HCl, $148 \mathrm{mM} \mathrm{NaCl}, \mathrm{pH}$ 7.4. Cohydrodynamic pressure: 20 mbar. Experimental conditions for $\mu_{e p}$ data: PB-coated capillary of $33.5 \mathrm{~cm}$ total length $(8.5 \mathrm{~cm}$ to the detector $) \times 50 \mu \mathrm{m}$ i.d. Buffer: $20 \mathrm{mM}$ TRIS-HCl, $148 \mathrm{mM} \mathrm{NaCl}, \mathrm{pH} 7.4$. Applied voltage: $-7.5 \mathrm{kV}$. Co-hydrodynamic pressure: -30 mbar. ${ }^{\mathrm{a}}$ Theoretical $p I$ according to the protein sequence.

\begin{tabular}{ccccc}
\hline & $p I$ & $\begin{array}{c}M \\
(\mathrm{kDa})\end{array}$ & $\begin{array}{c}R_{h} \\
(\mathrm{~nm})\end{array}$ & $\begin{array}{c}\mu_{e p} \\
\left(10^{-9} \mathrm{~m}^{2} \mathrm{~V}^{-1} \mathrm{~s}^{-1}\right)\end{array}$ \\
\hline lysozyme & $11^{71}$ & 14 & 2.0 & 10.6 \\
\hline Cyt C & $10^{72}$ & 12 & 1.8 & 8.8 \\
\hline RNase A & $9^{73}$ & 14 & 2.1 & 3.5 \\
\hline PrSA & $9^{\mathrm{a}}$ & 35 & 3.5 & 3.6 \\
\hline
\end{tabular}


The goal of the FACCE methodology is to quantify the free antigen concentration in various equilibrated antigen/adjuvant mixtures in order to plot the isotherm of adsorption at physiological $\mathrm{pH} 7.4$ and $165 \mathrm{mM}$ ionic strength. For that, the antigen/adjuvant mixture was placed at the outlet end of the capillary to reduce the analysis time, and the free antigen is electrokinetically and continuously introduced in the capillary (frontal mode). As shown in Figure 1A, the positively charged free antigen migrates to the negative pole, whereas the negatively charged antigenadjuvant complexes remain at the positive pole in the outlet vial. The effective electrophoretic mobilities of the proteins studied in this work are given in Table 1. To get repeatable results, the nature of the capillary coating, the capillary rinsing protocol and the composition of the electrolyte were carefully investigated. Lysozyme is well-known to be particularly difficult to analyze because it strongly adsorbs on the capillary walls even with capillary coatings ${ }^{74}$. Therefore, lysozyme was used to test different capillary coatings to limit adsorption phenomena on the capillary wall. Neutral and cationic coatings were compared: Hydroxypropylcellulose (HPC), Ultratrol ${ }^{\circledR} \quad$ LN, Polydiallyldimethylammonium chloride (PDADMAC), hexadimethrine bromide (polybrene, PB), a multilayer coating PB- Polystyrene sulfonate (PSS) PB capillary and two ready-to-use capillaries from Agilent Technologies $\mu$-SIL FC and DBWAX were tested. The best results in term of baseline stability and repeatability on migration times were obtained with the cationic PB coating. Lysozyme exhibited non-negligible absorption on all the neutral capillaries coatings tested leading to drift of the UV plateau in FACCE.

With a cationic coating, a co-pressure was applied to compensate the electroosmotic flow and to allow the protein migration to the detection window. The applied co-pressure was a crucial parameter which was carefully investigated to obtain stable baseline and repeatable measurements, as presented in detail in Figure SI1. The applied co-pressure should be neither too 
low nor too high to avoid the migration of the negatively charged complexes into the capillary. The selected co-hydrodynamic pressure giving the best results was - 30 mbars.

The capillary rinsing steps were also very important to avoid baseline drift, as presented in Figure SI2. So, the concomitant use of $0.5 \mathrm{M} \mathrm{NaOH}$ and $2 \mathrm{M} \mathrm{NaCl}$ allows a complete removing of the PB coating and the possibly adsorbed proteins from the capillary surface, within a minimum of time. The washed capillary can then be re-coated by PB for subsequent analysis. The overall rinsing protocol between analysis is about $16 \mathrm{~min}$, while the electrophoretic step lasts about 4 min, leading to a total analysis time of 20 min for one equilibrated mixture and a total analysis time of 12 hours to achieve a 12-points adsorption isotherm in triplicate.

Seeking to improve the method repeatability, a variation of $\mathrm{pH}$ in the $300 \mu \mathrm{L}$ equilibrated mixture during the FACCE experiment was observed due to the electrolysis reactions in the sample vial and due to the relatively low volume of sample used for the FACCE experiments. As shown in Table 2 , in the case of $20 \mathrm{mM}$ TRIS buffer in a $300 \mu \mathrm{L}$ sample volume, the $\mathrm{pH}$ drops from 7.4 to 4.4 in 15 minutes under $224 \mathrm{~V} / \mathrm{cm}$ electric field, which corresponds to the separation time required to perform three repetitions of the same sample. $\mathrm{pH}$ variations modify the charge of the ligand and the substrate and can thus impact the interactions. TRIS concentration was thus increased up to $80 \mathrm{mM}$ to limit the $\mathrm{pH}$ drift to about $\sim 0.1 \mathrm{pH}$ unit (see Table 1). For those who would be interested in working with lower sample volume (i.e. $150 \mu \mathrm{L}$ ), increasing the TRIS concentration was not sufficient unless setting very high concentrations (200 mM, see Table 1$)$, it is preferable to switch to HEPES buffer which has a higher buffer capacity than TRIS at pH 7.4. In the case of the present study, TRIS buffer was still chosen as it most commonly used in vaccines formulations. 
Table 2. Variation of the $\mathrm{pH}$ of the buffer as a function of the exposure duration at $224 \mathrm{~V} / \mathrm{cm}$ electric field. Applied voltage: $-7.5 \mathrm{kV}$ on $33.5 \mathrm{~cm}$ capillary length. Buffers: TRIS $\mathrm{HCl}$ or HEPES $\mathrm{NaOH}$ at various concentrations as indicated in the Table $+\mathrm{NaCl}$ to set the ionic strength at $165 \mathrm{mM}$. Temperature: $22^{\circ} \mathrm{C}$. Sample volume: $0.15 \mathrm{~mL}$ or $0.3 \mathrm{~mL}$ as indicated in the Table. The sample vials were only filled with the buffers and did not contained antigen-adjuvant mixtures. $n=3$ repetitions for TRIS $80 \mathrm{mM}$ and $n$ $=1$ for the others.

\begin{tabular}{ccccccc}
\hline \multirow{2}{*}{$\begin{array}{c}\text { Buffer } \\
(\mathrm{mM})\end{array}$} & $\begin{array}{c}\text { Volume } \\
(\mu \mathrm{L})\end{array}$ & \multicolumn{5}{c}{ Duration under electric field } \\
\cline { 3 - 7 } & & $0 \mathrm{~min}$ & $5 \mathrm{~min}$ & $10 \mathrm{~min}$ & $15 \mathrm{~min}$ & $\begin{array}{c}\Delta \mathrm{pH} \\
\text { for } 15 \mathrm{~min}\end{array}$ \\
\hline TRIS 20 & 300 & 7.4 & 7.2 & 6.9 & 4.4 & -3.0 \\
\hline TRIS 60 & 300 & 7.4 & 7.4 & 7.3 & 7.2 & -0.2 \\
\hline TRIS 80 & 300 & 7.4 & 7.4 & 7.3 & 7.3 & -0.1 \\
\hline TRIS 20 & 150 & 7.5 & 6.9 & 3.4 & 2.6 & -4.9 \\
\hline TRIS 100 & 150 & 7.4 & 7.3 & 7.2 & 7.1 & -0.3 \\
\hline TRIS 200 & 150 & 7.4 & 7.4 & 7.3 & 7.3 & -0.1 \\
\hline HEPES 100 & 150 & 7.4 & 7.4 & 7.3 & 7.3 & -0.1 \\
\hline
\end{tabular}

The optimized FACCE experimental conditions led to flat and repeatable fronts for the three model proteins and for the vaccine antigen. The method was first used to make calibration curves with the proteins alone. Very good linearities $\left(R^{2}\right.$ between 0.98 and 1.00$)$ were obtained for the three model proteins and the vaccine antigen. In all protein / adjuvant mixtures, the SPA09 concentration remains constant fixed at $1 \mathrm{~g} / \mathrm{L}$ and the protein concentration varies. As only the free protein migrates into the capillary, the height of the fronts obtained allows the quantification of the free protein. For instance, Figure 1B displays the electropherograms obtained in triplicate for the different equilibrated lysozyme / SPA09 mixtures. One can observe that the three measurements performed for each mixture overlap very well reflecting good repeatability of the method. 

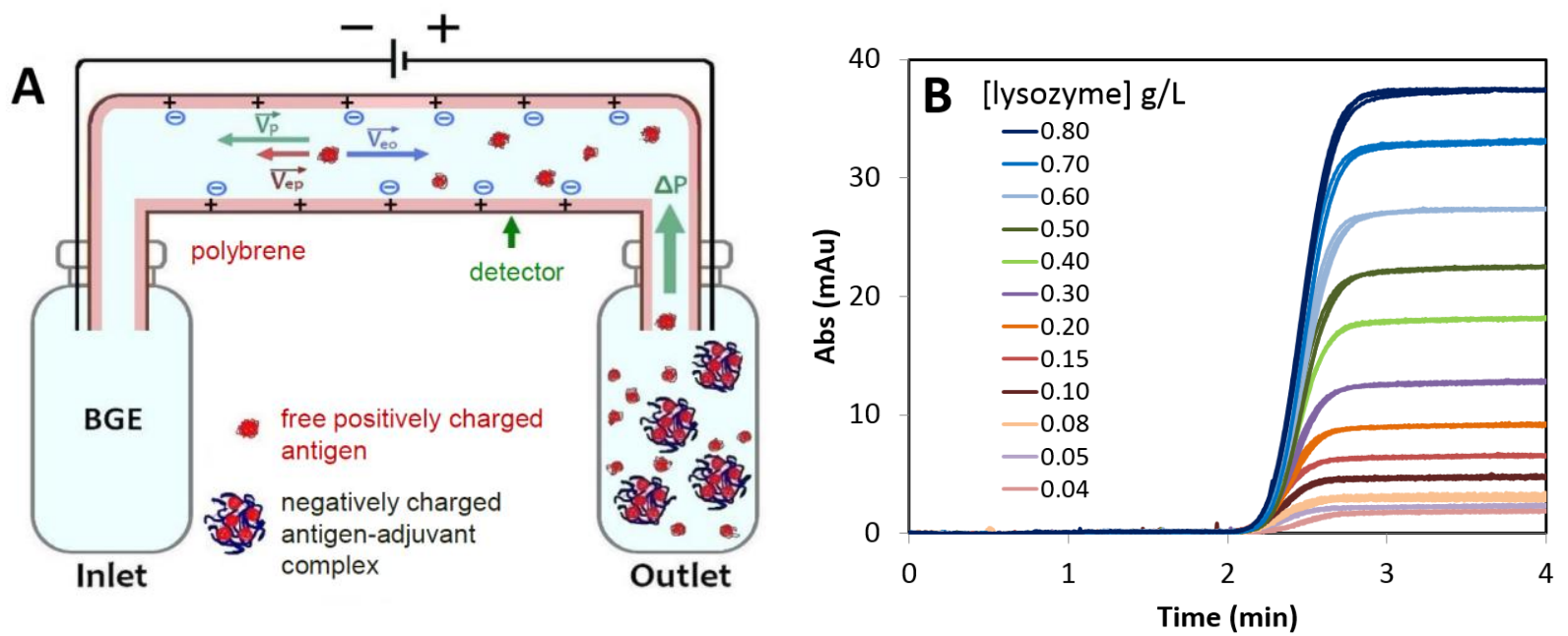

Figure 1. Schematic representation of the free antigen migration by FACCE (A) and the corresponding electropherograms (B) obtained for the detection of the free protein in different equilibrated protein/adjuvant mixtures (Lysozyme/SPA09). $V_{e o}$ represents the velocity of the electroosmotic flow, $V_{e p}$ is the velocity due to the effective electrophoretic mobility of free antigen and $V_{p}$ is the velocity due to the applied co-pressure. Experimental conditions: PB-coated capillary of $33.5 \mathrm{~cm}$ total length $(8.5 \mathrm{~cm}$ to the detector) $\times 50 \mu \mathrm{m}$ i.d. Buffer: $80 \mathrm{mM}$ TRIS-HCl, $97 \mathrm{mM} \mathrm{NaCl}, \mathrm{pH} 7.4$ (167 mM ionic strength). Applied voltage: $-7.5 \mathrm{kV}$ (from inlet). Co-hydrodynamic pressure: $-30 \mathrm{mbar}$ (from inlet). UV detection: $214 \mathrm{~nm}$. Temperature: $25{ }^{\circ} \mathrm{C}$. Samples $(300 \mu \mathrm{L})$ were prepared in the background electrolyte and placed at the outlet end of the capillary. SPA09 concentration in the final mixtures: $1 \mathrm{~g} / \mathrm{L}$. Protein concentration in the final mixtures: see the inset.

\section{Adsorption isotherms}

From the quantification of the free protein, the average number of bound proteins per adjuvant, $\bar{n}$, can be calculated using equation (1) and the adsorption isotherm can be plotted. If the mixtures are at equilibrium, the addition order should not modify the results ${ }^{70}$. The adsorption isotherms between SPA09 and lysozyme were plotted for both addition orders: SPA09 added into lysozyme and lysozyme added into SPA09. As shown in Figure SI2, the addition order did not influence the results. Therefore, it was assumed that the equilibrium in the sample mixture was reached. It is worth noting that the incubation time did not change the results that were obtained. 
Based on this FACCE methodology, the adsorption isotherms of the three model proteins (lysozyme, Cyt C and RNase A) were plotted in the basis of triplicates for 12 different concentrations, as displayed in Figure 2A. It can be observed that the three adsorption isotherms do not display any saturation plateau. Higher protein concentrations could not be reached experimentally due to protein solubilization limitations and precipitation concerns. For that reason, the $n$ value could not be directly obtained from the $\bar{n}$ value at saturation. To determine the binding parameters $(k$ and $n)$ in the framework of the model of independent site of equal energy, the first successive interaction constants $K_{l}$ were obtained from the slope at the origin of the isotherm (see equation (5)). This experimental determination allows a first ranking of the interactions: $K_{l \text { Cyt C }} \approx K_{l \text { RNase A }}>K_{l \text { Lysozyme. }} K_{l}$ represents the $n \times k$ product. To get the $n$ and $k$ values independently, the Scatchard representation was used to linearize the adsorption isotherm. A straight line was obtained, and the corresponding slope gave the intrinsic binding site constant $k$, as shown in Figure 2B. The obtained $k$ values varied between $6.7 \times 10^{3} \mathrm{M}^{-1}$ for lysozyme up to $1.3 \times 10^{4} \mathrm{M}^{-1}$ for RNase A. Knowing $K_{l}$, it was possible to estimate the number of independent interaction sites of the equal energy $(n)$ which varied between 75 for lysozyme and 149 for Cyt C. At saturation, this stoichiometry corresponds to $m=2.2 \mathrm{~g}$ for lysozyme and $3.0 \mathrm{~g}$ for Cyt $\mathrm{C}$ of protein per g of adjuvant. By replacing $n$ and $k$ in the expression of the Langmuir equation (4), the fits of the isotherms were represented by the dotted lines in Figure 2A, showing very good agreement with the experimental points.

Using the $n$ and $k$ experimental values, the free protein concentration can be calculated for any initial concentrations of protein and adjuvant introduced in the mixtures, using equation (8). For typical vaccine formulation having an initial antigen concentration of $0.4 \mathrm{~g} / \mathrm{L}$ and an adjuvant concentration of $1 \mathrm{~g} / \mathrm{L}$, the free protein concentrations were determined for each model protein 
(expressed in percentage of the free form relative to the introduced concentration) and varied between $33 \%$ and $55 \%$, see Table 3 . The average number of proteins $\bar{n}$ with these initial conditions are also given in Table 3 and varied between 6 and 13 proteins per polymer chain for lysozyme and Cyt $\mathrm{C}$, respectively. Of course, this stoichiometry depends on the molar mass of the polymer chain, and it is convenient to express it in mass ratio $\bar{m}$ corresponding to 0.18 to $0.26 \mathrm{~g}$ of protein per $\mathrm{g}$ of adjuvant for lysozyme and Cyt $\mathrm{C}$, respectively.
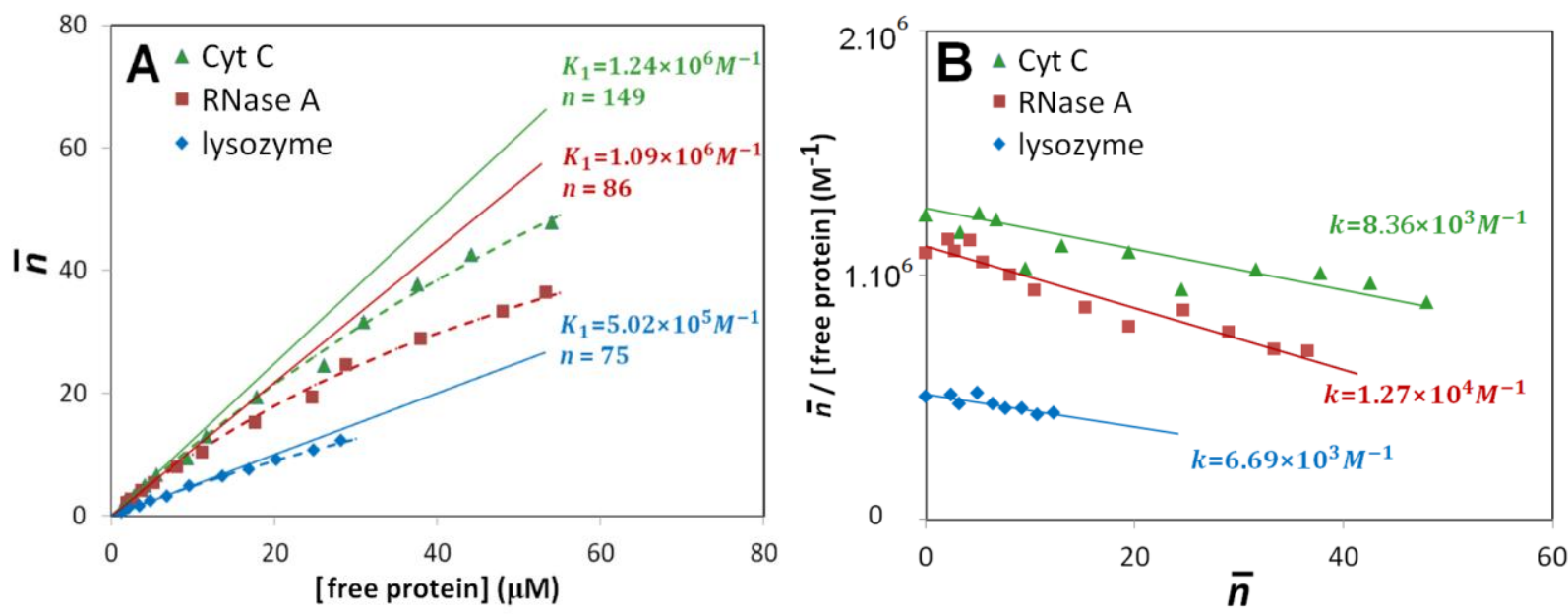

Figure 2. Isotherms of adsorption obtained by FACCE for the interaction between three model cationic proteins (lysozyme, RNase A, Cyt C) and anionic SPA09 $\left(M_{w}=583 \mathrm{kDa}\right)$ adjuvant (A) and the corresponding Scatchard plots (B). Fitting curves (dotted lines) were plotted with the $k$ and $n$ values reported in Table 2 using the model of independent sites of equal energy (equation (4)). Experimental conditions: SPA09 concentration in the final mixtures: $1 \mathrm{~g} / \mathrm{L}$. Cyt $\mathrm{C}$ and RNase A concentrations in the final mixtures: $0.08 ; 0.10 ; 0.15 ; 0.20 ; 0.30 ; 0.40 ; 0.60 ; 0.80 ; 1.00 ; 1.20 ; 1.40$ and $1.60 \mathrm{~g} / \mathrm{L}$. Lysozyme concentrations in the final mixtures: $0.04 ; 0.05 ; 0.08 ; 0.10 ; 0.15 ; 0.20 ; 0.35 ; 0.40 ; 0.50 ; 0.60 ; 0.70$ and $0.80 \mathrm{~g} / \mathrm{L}$. Other experimental conditions as in Figure 1. Each experimental data point was obtained in triplicate. Error bars are \pm one SD (generally too small to be seen). The tangent to the origin of the isotherms are represented in Figure 2A, the slope of which are related to $K_{l}$.

\section{Impact of the ionic strength on antigen-adjuvant interactions}

A strong dependence of protein/polyelectrolyte interactions with the ionic strength has been reported in the literature ${ }^{75-77}$. To study the impact of the ionic strength on the interaction, five buffers were prepared at $\mathrm{pH} 7.4$, with different ionic strengths ranging from 118 to $268 \mathrm{mM}$. The 
different ionic strengths were obtained by varying the $\mathrm{NaCl}$ concentration while keeping the TRIS concentration fixed at $80 \mathrm{mM}$. The calibration curves obtained with the five buffers had good linearities $\left(R^{2}\right.$ between 0.98 and 1.00). For an equivalent lysozyme $(0.4 \mathrm{~g} / \mathrm{L}) /$ SPA09 $(1 \mathrm{~g} / \mathrm{L})$ mixture: less than $17 \%$ free lysozyme was detected at $118 \mathrm{mM}$ ionic strength while more than $93 \%$ was detected at $268 \mathrm{mM}$ ionic strength. These results show the strong impact of the ionic strength on the interaction. This strong dependency can be visualized by the decreasing of the slope of the tangent at the origin (representing the first successive interactions constants $K_{l}$ ) in Figure $3 \mathrm{~A}$. Indeed, Figure $3 \mathrm{~A}$ shows that at $118 \mathrm{mM}$ ionic strength $K_{l}=3.15 \times 10^{6} \mathrm{M}^{-1}$, while at $268 \mathrm{mM}$ ionic strength $K_{l}=5.18 \times 10^{4} \mathrm{M}^{-1}$. By plotting $K_{l}$ against the ionic strength $I$ in double logarithmic scales (see Figure 3B), the slope of the line obtained is an estimation of the number of released counter-ions during the association of one protein onto an adjuvant chain (see equation (11)). In the case of lysozyme/SPA09 interaction, a -5 power law was obtained:

$$
K_{1}=a I^{-b}=4.90 \times 10^{16} I^{-5}
$$

where $K_{l}$ is expressed in $\mathrm{M}^{-1}$ and $I$ in $\mathrm{mM}$.

This means (see equation 11) that 5 counter-ions are released during the association of the first protein onto the adjuvant. A maximum in the protein/polyelectrolyte binding constant has been reported in the literature at $10-50 \mathrm{mM}$ ionic $\operatorname{strength}^{75-77}$. This maximum was explained by the balance between repulsive and attractive electrostatic forces due to the dipolar nature of proteins having positive and negative patches ${ }^{75}$. In our study, it would have been difficult to observe this maximum because the $K_{l}$ binding constant would be too high to be measurable around 10-50 mM ionic strength and below. 

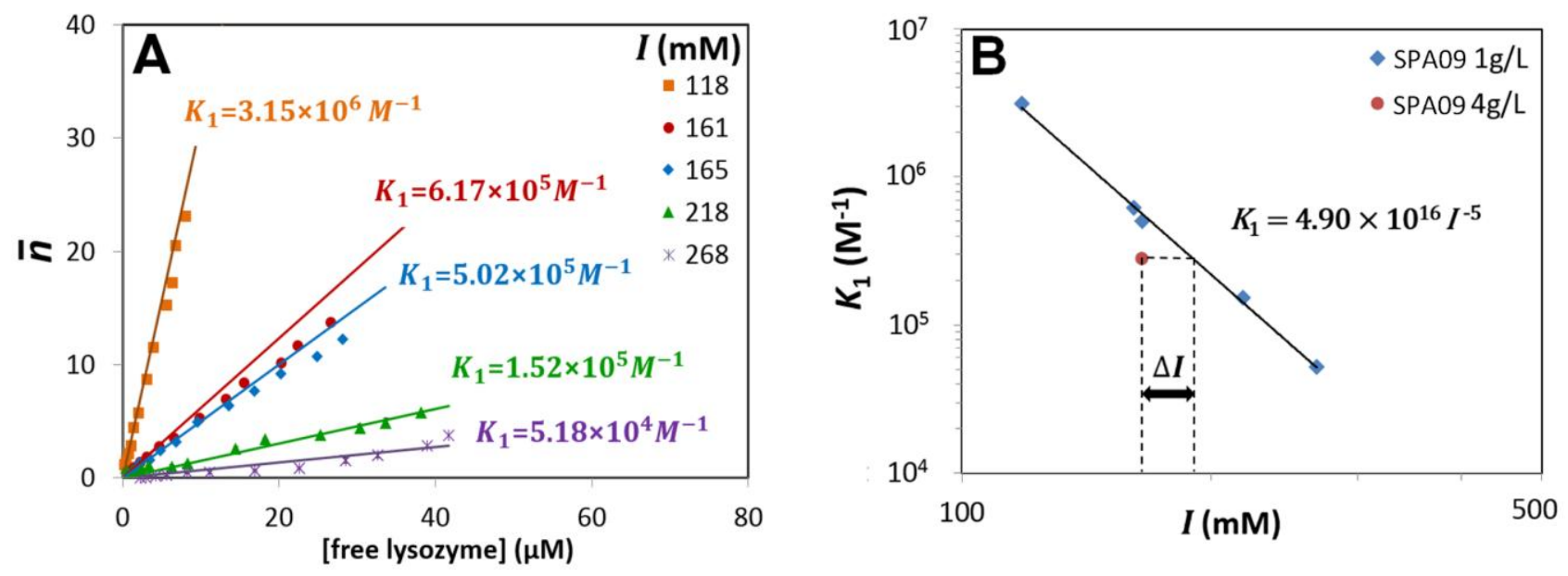

Figure 3. Impact of the ionic strength of the buffer on the isotherms of adsorption of lysozyme onto SPA09 (A) and the corresponding dependence of $K_{1}$ with the ionic strength (B). Experimental conditions: PB-coated capillary of $33.5 \mathrm{~cm}$ total length $(8.5 \mathrm{~cm}$ to the detector $) \times 50 \mu \mathrm{m}$ i.d. Buffer: $80 \mathrm{mM}$ TRIS$\mathrm{HCl}, \mathrm{pH} 7.4$, with various $\mathrm{NaCl}$ concentrations to set the ionic strength as indicated on the graphs. Applied voltage: $-7.5 \mathrm{kV}$. Co-hydrodynamic pressure: -30 mbar. UV detection: $214 \mathrm{~nm}$. Temperature: $25{ }^{\circ} \mathrm{C}$. Samples were prepared in the background electrolyte by 50/50 (v/v) dilutions of SPA09 and lysozyme stock solutions. SPA09 concentration in the final mixtures: $1 \mathrm{~g} / \mathrm{L}$. Lysozyme concentrations in the final mixtures: $0.04 ; 0.05 ; 0.08 ; 0.10 ; 0.15 ; 0.20 ; 0.35 ; 0.40 ; 0.50 ; 0.60 ; 0.70$ and $0.80 \mathrm{~g} / \mathrm{L}$.

\section{Impact of the adjuvant concentration on the interactions}

Theoretically, the adjuvant concentration should not affect the adsorption isotherm since the isotherm of adsorption should be valid whatever the initial concentrations in protein and adjuvant introduced in the mixtures, as far as the mixture remains at equilibrium. As the adjuvant concentration is a parameter which is often modified and adjusted during the formulation of a vaccine it is interesting to look at the results obtained with another adjuvant concentration. Two adsorption isotherms were plotted at $1 \mathrm{~g} / \mathrm{L}$ and $4 \mathrm{~g} / \mathrm{L}$ of SPA09 in the mixture and at $165 \mathrm{mM}$ ionic strength (see Figure 4). However, by plotting the two adsorption isotherms at $1 \mathrm{~g} / \mathrm{L}$ and $4 \mathrm{~g} / \mathrm{L}$ of SPA09 in the mixture at $165 \mathrm{mM}$, no overlapping was observed, as shown in Figure 4. This discrepancy can be explained by the change in ionic strength brought by the polymeric adjuvant itself, since this contribution was not taken into account in the calculation of the ionic strength. In 
order to estimate the ionic strength increment provided by the difference in SPA09 concentration of $3 \mathrm{~g} / \mathrm{L}$, the $K_{1}$ value obtained experimentally at $4 \mathrm{~g} / \mathrm{L}$ SPA09 was represented in Figure 3, and the increment of ionic strength $\Delta I$ can be directly estimated from the ionic strength dependence obtained in the previous section (see Figure 3) according to:

$$
\Delta I=\left(\frac{K_{1}^{a t P A A=4 g / L}}{a}\right)^{-\frac{1}{b}}-I_{B G E}
$$

where $I_{B G E}$ is the ionic strength of the BGE without taking into account the SPA09 contribution (here $165 \mathrm{mM}$ ). Taking $K_{1}^{\text {at } P A A=4 g / L}=2.78 \times 10^{5} \mathrm{M}^{-1}$ and $I_{B G E}=165 \mathrm{mM}$ in equation (13) leads to the conclusion that an addition of $3 \mathrm{~g} / \mathrm{L}$ SPA09 is equivalent to an increase in the ionic strength of $\Delta I \sim 26 \mathrm{mM}$. To confirm this result, a buffer solution with an ionic strength of $165-26=139$ $\mathrm{mM}$ was then prepared to determine the isotherm of adsorption of lysozyme with $4 \mathrm{~g} / \mathrm{L} \mathrm{SPA09.}$ Figure 4 shows that the adsorption isotherm describing the interactions between lysozyme and SPA09 at $4 \mathrm{~g} / \mathrm{L}$ in a $139 \mathrm{mM}$ ionic strength buffer is very close to the adsorption isotherm using SPA09 at $1 \mathrm{~g} / \mathrm{L}$ in a $165 \mathrm{mM}$ ionic strength buffer, with difference in slope less than $2 \%$. These results validate both the ionic strength dependence found in the previous section and the way to experimentally estimate the SPA09 adjuvant contribution to the ionic strength. 


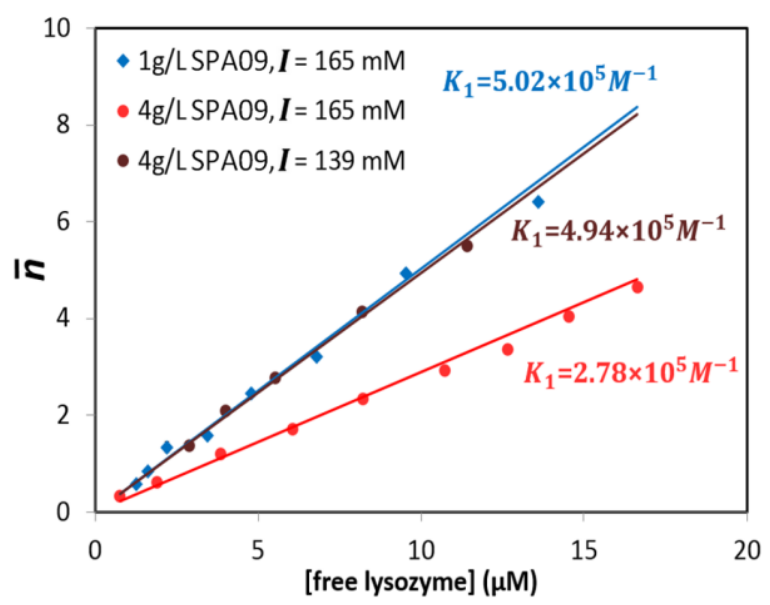

Figure 4. Influence of the SPA09 concentration on the isotherm of adsorption of lysozyme on SPA09. Experimental conditions: PB-coated capillary of $33.5 \mathrm{~cm}$ total length $(8.5 \mathrm{~cm}$ to the detector $) \times 50 \mu \mathrm{m}$ i.d. Buffer: $80 \mathrm{mM}$ TRIS-HCl, $\mathrm{pH} 7.4$, with various $\mathrm{NaCl}$ concentrations to the ionic strength indicated on the graph (SPA09 contribution to the ionic strength is not considered). Applied voltage: $-7.5 \mathrm{kV}$. Cohydrodynamic pressure: -30 mbar. UV detection: $214 \mathrm{~nm}$. Temperature: $25{ }^{\circ} \mathrm{C}$. SPA09 concentration in the final mixtures: $1 \mathrm{~g} / \mathrm{L}$ or $4 \mathrm{~g} / \mathrm{L}$. Lysozyme concentrations in the final mixtures: $0.04 ; 0.05 ; 0.08 ; 0.10$; $0.15 ; 0.20 ; 0.35$ and $0.40 \mathrm{~g} / \mathrm{L}$ for the isotherm obtained with SPA09 at $1 \mathrm{~g} / \mathrm{L}, 0.08 ; 0.10 ; 0.20 ; 0.30 ; 0.40$; 0.70 and $0.80 \mathrm{~g} / \mathrm{L}$ for the isotherm obtained with SPA09 at $4 \mathrm{~g} / \mathrm{L}$.

\section{Impact of the adjuvant molar mass}

The results obtained with SPA09 adjuvant provided by Sanofi-Pasteur (polyacrylic acid, $\left.M_{w}=590 \mathrm{kDa}\right)$ were compared to those obtained with a polyacrylic acid of lower molar mass (PAA190, $M_{w}=190 \mathrm{kDa}$ ) purchased from Polymer Source. The adsorption isotherms of lysozyme, Cyt $\mathrm{C}$ and RNase A are plotted in Figure 5 for the two polyacrylic acids. The isotherms were distinct when the stoichiometry $\bar{n}$ was expressed in mol/mol (Figure 5A), which was expected since longer polyacrylic acid chain can interact with more proteins. In contrast, the differences between isotherms vanished when $\bar{n}$ was replaced by $\bar{m}$ expressed in g/g (Figure 5B). These results demonstrate that the parameters of interaction determined with a polyacrylic acid of given molar mass can be used for various polyacrylic acid as far as the isotherm of adsorption is expressed in $\mathrm{g} / \mathrm{g}$; and can be recalculated in $\mathrm{mol} / \mathrm{mol}$ if the average molar mass of the polyacrylic acid is known. 

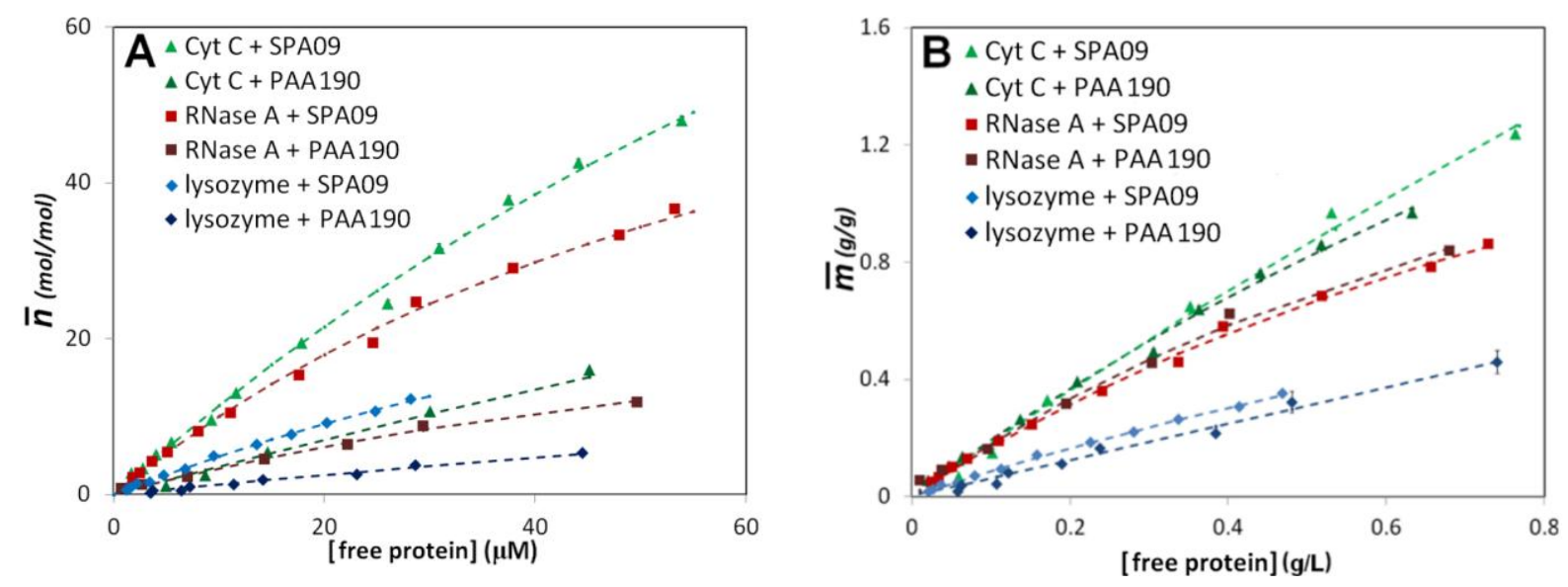

Figure 5. Influence of the adjuvant molar mass on the isotherm of adsorption of lysozyme onto polyacrylic acid for stoichiometries expressed in mol/mol (A) or in $\mathrm{g} / \mathrm{g}$ (B). Experimental conditions as in Figure 1.

\section{The case of the vaccine antigen in development}

The same FACCE method was applied to study interactions of SPA09 adjuvant with a vaccine antigen in development for the treatment of Staphylococcus aureus (PrSA). The calibration curve showed very good linearity $\left(R^{2}=1.00\right)$. As expected, due to the positive protein charge at $\mathrm{pH} 7.4$, less than $40 \%$ free PrSA was quantified on the concentration range studied, confirming the presence of PrSA - SPA09 interactions. The adsorption isotherm was plotted with triplicate measurements for each experimental point, as shown in Figure 6. The binding parameters were determined as described in previous section, leading to $K_{l}=1.5 \times 10^{6} \mathrm{M}^{-1}$, $n=28$, and $k=5.2 \times 10^{4} \mathrm{M}^{-1}$, see Table 3 . Comparing these results to the previously obtained results, it appears that the interaction parameters $K_{l}$ and $k$ obtained for PrSA are both higher to those obtained for the three model proteins while the maximum stoichiometry is in the order $n_{\text {Cyt C }}>n_{\text {lysozyme }} \approx n_{\text {RNase A }}>n_{P r S A}$. The ranking of the number of independent interaction sites $(n)$ is inversely proportional to the proteins size (see Table 1), which can be partly explained by the steric hindrance. Nevertheless, if we consider the maximum stoichiometry expressed in $g$ of protein per $\mathrm{g}$ of adjuvant $(\mathrm{m})$ the results are much closer, around $2 \mathrm{~g}$ of protein per $\mathrm{g}$ of adjuvant. 


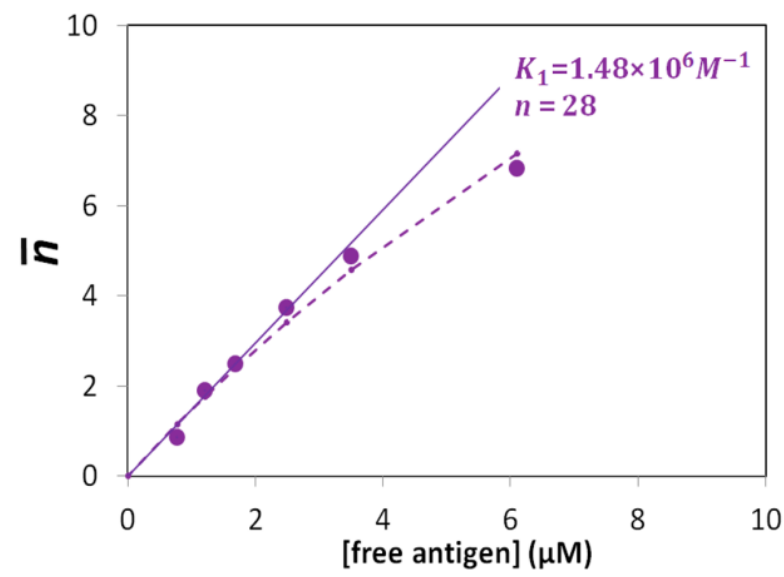

Figure 6. Isotherm of adsorption obtained by FACCE for the interaction between PrSA antigen and anionic SPA09 adjuvant. Experimental conditions: SPA09 concentration in the final mixtures: $1 \mathrm{~g} / \mathrm{L}$. PrSA concentrations in the final mixtures: $0.08 ; 0.15 ; 0.20 ; 0.30 ; 0.40$ and $0.60 \mathrm{~g} / \mathrm{L}$. Fitting curve using the model of independent sites of equal energy is represented in dotted lines. Other experimental conditions as in Figure 1.

Table 3. Binding parameters $(k, n)$ determined from the adsorption isotherms (see Figure 2) using the model of independent sites of equal energy. $K_{l}=n \times k$ is the first successive interaction constant and was determined from the slope at the origin of the isotherms. $k$ was obtained using the Scatchard representation (from the slopes of the lines in Figure 2B). Experimental conditions as in Figure 1. ${ }^{a}$ [antigen $]_{0}=0.4 \mathrm{~g} / \mathrm{L}$, $[\text { adjuvant }]_{0}=1 \mathrm{~g} / \mathrm{L}$.

\begin{tabular}{|c|c|c|c|c|}
\hline & Cyt C & RNase A & Lysozyme & PrSA \\
\hline $\begin{array}{l}\text { \% free antigen in } \\
\text { formulation }^{a}\end{array}$ & $33.9 \pm 1.0$ & $38.1 \pm 1.4$ & $55.2 \pm 0.2$ & $29.2 \pm 0.7$ \\
\hline $\begin{array}{l}\bar{n}(\mathrm{~mol} / \mathrm{mol}){ }^{i n} \\
\text { formulation }^{a}\end{array}$ & $13.0 \pm 0.2$ & $10.4 \pm 0.2$ & $6.4 \pm 0.1$ & $4.9 \pm 0.1$ \\
\hline $\begin{array}{c}\bar{m}(\mathrm{~g} / \mathrm{g}) \text { in } \\
\text { formulation }^{a}\end{array}$ & $(2.6 \pm 0.1) \times 10^{-1}$ & $(2.5 \pm 0.1) \times 10^{-1}$ & $(1.8 \pm 0.1) \times 10^{-1}$ & $(2.9 \pm 0.1) \times 10^{-1}$ \\
\hline$K_{l}\left(\mathrm{M}^{-1}\right)$ & $(1.2 \pm 0.1) \times 10^{6}$ & $(1.1 \pm 0.1) \times 10^{6}$ & $(5.0 \pm 0.6) \times 10^{5}$ & $(1.5 \pm 0.1) \times 10^{6}$ \\
\hline$k\left(\mathrm{M}^{-1}\right)$ & $(8.4 \pm 2.1) \times 10^{3}$ & $(1.3 \pm 0.1) \times 10^{4}$ & $(6.7 \pm 1.6) \times 10^{3}$ & $(5.2 \pm 2.0) \times 10^{4}$ \\
\hline$n(\mathrm{~mol} / \mathrm{mol})$ & $149 \pm 51$ & $86 \pm 12$ & $75 \pm 26$ & $28 \pm 12$ \\
\hline$m(\mathrm{~g} / \mathrm{g})$ & $3.0 \pm 1.0$ & $2.0 \pm 0.3$ & $2.2 \pm 0.7$ & $1.7 \pm 0.7$ \\
\hline
\end{tabular}




\section{Conclusion}

This work showed the suitability of FACCE method to study antigen-adjuvant interactions in vaccine products. FACCE gives a rapid and direct access to the percentage of free antigens and to the average number of bound antigens per adjuvant in vaccine formulations. Mathematical models allowed to further determine the maximum stoichiometry and the intrinsic binding constant, which are key parameters characterizing the interactions. FACCE method can also be used to follow vaccines stability and to optimize vaccines formulations, by monitoring the impact of the physicochemical parameters (excipients, adjuvant concentration, $\mathrm{pH}$, ionic strength) on the interaction stoichiometry and intrinsic binding constant. Ionic strength was found to be a crucial parameter having a considerable impact on the interaction parameters. It was also shown that the polymeric adjuvant itself significantly contributes to the ionic strength of the medium, and therefore, to the strength of the interactions. Its contribution could be estimated and corrected when formulating a vaccine product.

Regarding its limitations, the methodology developed in this work is well suited for the study of non-specific interactions with intrinsic binding site constant $k$ in the order of $10^{3}-10^{6} \mathrm{M}^{-1}$. For higher affinity binding site constant, a fluorescent detector would be required (with fluorescent antigen / protein) to lower the limit of quantification. Moreover, this methodology is only applicable when the free antigen/protein and the complex have significantly different electrophoretic mobilities. This methodology could also be used to study negatively charged antigens or other types of charged polymer adjuvants (cationic or neutral), but the method should be adapted especially by changing the capillary coating to avoid any undesirable adsorptions. FACCE methodology is, of course, not limited to antigen / adjuvant interaction, and can be applied for other applications in biomacromolecular science. 
The study of antigen-adjuvant interactions can allow a better understanding of adjuvants mode of action and their impact on the immunogenicity. Understanding antigen-adjuvant interactions at molecular level is necessary for the development of new adjuvants which goes hand in hand with the development of new vaccines.

\section{Acknowledgments}

This work was partly funded by Sanofi Pasteur, under a Cooperative Research and Development Agreement with the University of Montpellier and the CNRS.

\section{Supporting Information}

Influence of the co-hydrodynamic pressure on the adsorption. Optimization of the capillary washing conditions. Adsorption isotherms of lysozyme on SPA09 for both addition orders. 


\section{References}

(1) Rappuoli, R.; Pizza, M.; Del Giudice, G.; De Gregorio, E. Vaccines, New Opportunities for a New Society. Proc. Natl. Acad. Sci. 2014, 111 (34), 12288-12293. https://doi.org/10.1073/pnas.1402981111.

(2) WHO. Better Supply Systems Key to Reach All Children with Life-Saving Vaccines [Online], 2013.

https://www.who.int/mediacentre/news/releases/2013/world_immunization_week_2013041 8/en/Accessed March 242020.

(3) Piot, P.; Larson, H. J.; O’Brien, K. L.; N'kengasong, J.; Ng, E.; Sow, S.; Kampmann, B. Immunization: Vital Progress, Unfinished Agenda. Nature 2019, 575 (7781), 119-129. https://doi.org/10.1038/s41586-019-1656-7.

(4) Maruggi, G.; Zhang, C.; Li, J.; Ulmer, J. B.; Yu, D. MRNA as a Transformative Technology for Vaccine Development to Control Infectious Diseases. Mol. Ther. 2019, 27 (4), 757-772. https://doi.org/10.1016/j.ymthe.2019.01.020.

(5) Rothan, H. A.; Byrareddy, S. N. The Epidemiology and Pathogenesis of Coronavirus Disease (COVID-19) Outbreak. J. Autoimmun. 2020, 102433, 1-4. https://doi.org/10.1016/j.jaut.2020.102433.

(6) He, Y.; Yuan, Q.; Mathieu, J.; Stadler, L.; Senehi, N.; Sun, R.; Alvarez, P. J. J. Antibiotic Resistance Genes from Livestock Waste: Occurrence, Dissemination, and Treatment. Npj Clean Water 2020, 3 (1), 1-11. https://doi.org/10.1038/s41545-020-0051-0.

(7) Hwang, W.; Yoon, S. S. Virulence Characteristics and an Action Mode of Antibiotic Resistance in Multidrug-Resistant Pseudomonas Aeruginosa. Sci. Rep. 2019, 9 (1), 1-15. https://doi.org/10.1038/s41598-018-37422-9.

(8) Scoffone, V. C.; Barbieri, G.; Buroni, S.; Scarselli, M.; Pizza, M.; Rappuoli, R.; Riccardi, G. Vaccines to Overcome Antibiotic Resistance: The Challenge of Burkholderia Cenocepacia. Trends Microbiol. 2020, 28 (4), 315-326. https://doi.org/10.1016/j.tim.2019.12.005.

(9) Buchy, P.; Ascioglu, S.; Buisson, Y.; Datta, S.; Nissen, M.; Tambyah, P. A.; Vong, S. Impact of Vaccines on Antimicrobial Resistance. Int. J. Infect. Dis. 2020, 90, 188-196. https://doi.org/10.1016/j.ijid.2019.10.005.

(10) Yang, F.; Shi, K.; Jia, Y.; Hao, Y.; Peng, J.; Qian, Z. Advanced Biomaterials for Cancer Immunotherapy. Acta Pharmacol. Sin. 2020, 0, 1-17. https://doi.org/10.1038/s41401-0200372-z.

(11) Behzadi, E.; Halabian, R.; Hosseini, H. M.; Fooladi, A. A. I. Bacterial Toxin's DNA Vaccine Serves as a Strategy for the Treatment of Cancer, Infectious and Autoimmune Diseases. Microb. Pathog. 2016, 100, 184-194. https://doi.org/10.1016/j.micpath.2016.09.017.

(12) Solinas, C.; Aiello, M.; Migliori, E.; Willard-Gallo, K.; Emens, L. A. Breast Cancer Vaccines: Heeding the Lessons of the Past to Guide a Path Forward. Cancer Treat. Rev. 2020, 84, 101947. https://doi.org/10.1016/j.ctrv.2019.101947.

(13) Jahanafrooz, Z.; Baradaran, B.; Mosafer, J.; Hashemzaei, M.; Rezaei, T.; Mokhtarzadeh, A.; Hamblin, M. R. Comparison of DNA and MRNA Vaccines against Cancer. Drug Discov. Today 2020, 25 (3), 552-560. https://doi.org/10.1016/j.drudis.2019.12.003.

(14) Liu, T.-Y.; Hussein, W. M.; Jia, Z.; Ziora, Z. M.; McMillan, N. A. J.; Monteiro, M. J.; Toth, I.; Skwarczynski, M. Self-Adjuvanting Polymer-Peptide Conjugates As Therapeutic 
Vaccine Candidates against Cervical Cancer. Biomacromolecules 2013, 14 (8), 27982806. https://doi.org/10.1021/bm400626w.

(15) Kaslow, D. C.; Black, S.; Bloom, D. E.; Datla, M.; Salisbury, D.; Rappuoli, R. Vaccine Candidates for Poor Nations Are Going to Waste. Nature 2018, 564 (7736), 337-339. https://doi.org/10.1038/d41586-018-07758-3.

(16) Pasquale, A.; Preiss, S.; Silva, F.; Garçon, N. Vaccine Adjuvants: From 1920 to 2015 and Beyond. Vaccines 2015, 3 (2), 320-343. https://doi.org/10.3390/vaccines3020320.

(17) Garçon, N.; Friede, M. Evolution of Adjuvants Across the Centuries. In Plotkin's Vaccines (Chapter 6); 2018; pp 61-74.

(18) Watkinson, A.; Soliakov, A.; Ganesan, A.; Hirst, K.; LeButt, C.; Fleetwood, K.; Fusco, P. C.; Fuerst, T. R.; Lakey, J. H. Increasing the Potency of an Alhydrogel-Formulated Anthrax Vaccine by Minimizing Antigen-Adjuvant Interactions. Clin. Vaccine Immunol. 2013, 20 (11), 1659-1668. https://doi.org/10.1128/CVI.00320-13.

(19) Visan, L.; Sanchez, V.; Kania, M.; de Montfort, A.; de la Maza, L. M.; Ausar, S. F. Phosphate Substitution in an AlOOH - TLR4 Adjuvant System (SPA08) Modulates the Immunogenicity of Serovar E MOMP from Chlamydia Trachomatis. Hum. Vaccines Immunother. 2016, 12 (9), 2341-2350. https://doi.org/10.1080/21645515.2016.1168958.

(20) Egan, P. M.; Belfast, M. T.; Giménez, J. A.; Sitrin, R. D.; Mancinelli, R. J. Relationship between Tightness of Binding and Immunogenicity in an Aluminum-Containing AdjuvantAdsorbed Hepatitis B Vaccine. Vaccine 2009, 27 (24), 3175-3180. https://doi.org/10.1016/j.vaccine.2009.03.054.

(21) Hansen, B.; Sokolovska, A.; HogenEsch, H.; Hem, S. L. Relationship between the Strength of Antigen Adsorption to an Aluminum-Containing Adjuvant and the Immune Response. Vaccine 2007, 25 (36), 6618-6624. https://doi.org/10.1016/j.vaccine.2007.06.049.

(22) Hansen, B.; Belfast, M.; Soung, G.; Song, L.; Egan, P. M.; Capen, R.; HogenEsch, H.; Mancinelli, R.; Hem, S. L. Effect of the Strength of Adsorption of Hepatitis B Surface Antigen to Aluminum Hydroxide Adjuvant on the Immune Response. Vaccine 2009, 27 (6), 888-892. https://doi.org/10.1016/j.vaccine.2008.11.078.

(23) Hansen, B.; Malyala, P.; Singh, M.; Sun, Y.; Srivastava, I.; Hogenesch, H.; Hem, S. L. Effect of the Strength of Adsorption of HIV 1 SF162dV2gp140 to Aluminum-containing Adjuvants on the Immune Response. J. Pharm. Sci. 2011, 100 (8), 3245-3250. https://doi.org/10.1002/jps.22555.

(24) Dey, A. K.; Malyala, P.; Singh, M. Physicochemical and Functional Characterization of Vaccine Antigens and Adjuvants. Expert Rev. Vaccines 2014, 13 (5), 671-685. https://doi.org/10.1586/14760584.2014.907528.

(25) Reed, S. G.; Orr, M. T.; Fox, C. B. Key Roles of Adjuvants in Modern Vaccines. Nat. Med. 2013, 19 (12), 1597-1608. https://doi.org/10.1038/nm.3409.

(26) Fox, C. B.; Kramer, R. M.; Barnes V, L.; Dowling, Q. M.; Vedvick, T. S. Working Together: Interactions between Vaccine Antigens and Adjuvants. Ther. Adv. Vaccines 2013, 1 (1), 7-20. https://doi.org/10.1177/2051013613480144.

(27) Diamantstein, T., Wagner, B., Beyse, I., Odenwald, M.V., Schultz, G. Stimulation of Humoral Antibody Formation by Polyanions. The Effect of Polyacrylic Acid on the Primary Immune Response in Mice Immunized with Sheep Red Blood Cells. Eur. J. Immunol. 1971, 335-340. https://doi.org/10.1002/eji.1830010506.

(28) Kreuter, J.; Haenzel, I. Mode of Action of Immunological Adjuvants: Some Physicochemical Factors Influencing the Effectivity of Polyacrylic Adjuvants. Infect. Immun. 1978, 19 (2), 667-675. https://doi.org/10.1128/IAI.19.2.667-675.1978. 
(29) Hilgers, L. A. Th.; Nicolas, I.; Lejeune, G.; Dewil, E.; Strebelle, M.; Boon, B. Alkyl-Esters of Polyacrylic Acid as Vaccine Adjuvants. Vaccine 1998, 16 (16), 1575-1581. https://doi.org/10.1016/S0264-410X(98)00047-4.

(30) Hilgers, L. A. T.; Ghenne, L.; Nicolas, I.; Fochesato, M.; Lejeune, G.; Boon, B. AlkylPolyacrylate Esters Are Strong Mucosal Adjuvants. Vaccine 2000, 18 (28), 3319-3325. https://doi.org/10.1016/S0264-410X(00)00114-6.

(31) Kabanov, V. A. From Synthetic Polyelectrolytes to Polymer-Subunit Vaccines. Pure Appl. Chem. 2004, 76 (9), 1659-1677. https://doi.org/10.1351/pac200476091659.

(32) Parker, R.; Deville, S.; Dupuis, L.; Bertrand, F.; Aucouturier, J. Adjuvant Formulation for Veterinary Vaccines: Montanide ${ }^{\mathrm{TM}}$ Gel Safety Profile. Procedia Vaccinol. 2009, 1 (1), 140-147. https://doi.org/10.1016/j.provac.2009.07.026.

(33) Vialle, R.; Dupuis, L.; Deville, S.; Bertrand, F.; Gaucheron, J.; Aucouturier, J. Microgel Particulate Adjuvant: Characterisation and Mechanisms of Action. Procedia Vaccinol. 2010, 2 (1), 12-16. https://doi.org/10.1016/j.provac.2010.03.003.

(34) Mumford, J. A.; Wilson, H.; Hannant, D.; Jessett, D. M. Antigenicity and Immunogenicity of Equine Influenza Vaccines Containing a Carbomer Adjuvant. Epidemiol. Infect. 1994, 112 (02), 421-437. https://doi.org/10.1017/S0950268800057848.

(35) Gelfi, J.; Pappalardo, M.; Claverys, C.; Peralta, B.; Guérin, J.-L. Safety and Efficacy of an Inactivated Carbopol-Adjuvanted Goose Haemorrhagic Polyomavirus Vaccine for Domestic Geese. Avian Pathol. 2010, 39 (2), 111-116. https://doi.org/10.1080/03079451003604647.

(36) Zhang, J.; Wang, M.; Zhou, N.; Shen, Y.; Li, Y. Evaluation of Carbopol as an Adjuvant on the Effectiveness of Progressive Atrophic Rhinitis Vaccine. Vaccine 2018, 36 (30), $4477-$ 4484. https://doi.org/10.1016/j.vaccine.2018.06.023.

(37) Cotte, J.-F.; Bouadam, A.; Sordoillet, A.; Jaudinaud, I.; Chambon, V.; Talaga, P. Determination of Molecular Size Parameters and Quantification of Polyacrylic Acid by High Performance Size-Exclusion Chromatography with Triple Detection. Anal. Bioanal. Chem. 2017, 409 (8), 2083-2092. https://doi.org/10.1007/s00216-016-0155-z.

(38) Dey, A. K.; Burke, B.; Sun, Y.; Hartog, K.; Heeney, J. L.; Montefiori, D.; Srivastava, I. K.; Barnett, S. W. Use of a Polyanionic Carbomer, Carbopo1971P, in Combination with MF59, Improves Antibody Responses to HIV-1 Envelope Glycoprotein. Vaccine 2012, 30 (17), 2749-2759. https://doi.org/10.1016/j.vaccine.2012.02.027.

(39) Wegmann, F.; Moghaddam, A. E.; Schiffner, T.; Gartlan, K. H.; Powell, T. J.; Russell, R. A.; Baart, M.; Carrow, E. W.; Sattentau, Q. J. The Carbomer-Lecithin Adjuvant Adjuplex Has Potent Immunoactivating Properties and Elicits Protective Adaptive Immunity against Influenza Virus Challenge in Mice. Clin. Vaccine Immunol. 2015, 22 (9), 1004-1012. https://doi.org/10.1128/CVI.00736-14.

(40) Bonam, S. R.; Partidos, C. D.; Halmuthur, S. K. M.; Muller, S. An Overview of Novel Adjuvants Designed for Improving Vaccine Efficacy. Trends Pharmacol. Sci. 2017, 38 (9), 771-793. https://doi.org/10.1016/j.tips.2017.06.002.

(41) Nevagi, R. J.; Skwarczynski, M.; Toth, I. Polymers for Subunit Vaccine Delivery. Eur. Polym. J. 2019, 114, 397-410. https://doi.org/10.1016/j.eurpolymj.2019.03.009.

(42) Rigaut, G.; Parisot, A.; De Luca, K.; Andreoni, C.; Remolue, L.; Garinot, M.; Cotte, J.-F.; Probeck-Quellect, P.; Haensler, J.; Chambon, V.; Talaga, P. Novel Immunogenic Formulations Comprising Linear or Branched Polyacrylic Acid Polymer Adjuvants. Patent WO/2017/218819 2017. 
(43) Bommier, E.; Chapat, L.; Guiot, A. L.; Hilaire, F.; Cariou, C.; Poulet, H.; Pialot, D.; De Luca, K. Multivariate Analysis of the Immune Response to Different Rabies Vaccines. Vet. Immunol. Immunopathol. 2020, 220, 109986. https://doi.org/10.1016/j.vetimm.2019.109986.

(44) O’Brien, R.; Frasca, V.; Arsenault, M.; Wojtusik, M. J. Aluminum Phosphate Adsorption of Proteins Using Isothermal Titration Calorimetry. Biophys. J. 2011, 100 (3), 553a. https://doi.org/10.1016/j.bpj.2010.12.3220.

(45) Kim, K. H.; Lee, E. K. Biothermodynamic Analysis of BSA Adsorption to Alum Gel Using Isothermal Titration Calorimetry. Biotechnol. Bioprocess Eng. 2007, 12 (4), 366. https://doi.org/10.1007/BF02931058.

(46) Lounis, F. M.; Chamieh, J.; Leclercq, L.; Gonzalez, P.; Geneste, A.; Prelot, B.; Cottet, H. Interactions between Oppositely Charged Polyelectrolytes by Isothermal Titration Calorimetry: Effect of Ionic Strength and Charge Density. J. Phys. Chem. B 2017, 121 (12), 2684-2694. https://doi.org/10.1021/acs.jpcb.6b11907.

(47) Yang, Y.; Zhao, Q.; Li, Z.; Sun, L.; Ma, G.; Zhang, S.; Su, Z. Stabilization Study of Inactivated Foot and Mouth Disease Virus Vaccine by Size-Exclusion HPLC and Differential Scanning Calorimetry. Vaccine 2017, 35 (18), 2413-2419. https://doi.org/10.1016/j.vaccine.2017.03.037.

(48) Wei, Y.; Xiong, J.; Larson, N. R.; Iyer, V.; Sanyal, G.; Joshi, S. B.; Volkin, D. B.; Middaugh, C. R. Effect of 2 Emulsion-Based Adjuvants on the Structure and Thermal Stability of Staphylococcus Aureus Alpha-Toxin. J. Pharm. Sci. 2018, 107 (9), 23252334. https://doi.org/10.1016/j.xphs.2018.05.019.

(49) Siguier, J. P.; Major, M.; Balland, O. Development of a New Method to Characterize $\left(\mathrm{SMBV}^{\mathrm{TM}}\right)$ Antigen Formulations Using Surface Plasmon Resonance Technology. Int. J. Pharm. 2002, 242 (1-2), 411-415. https://doi.org/10.1016/S0378-5173(02)00227-2.

(50) Seyrek, E.; Hattori, T.; Dubin, P. L. Frontal Analysis Continuous Capillary Electrophoresis for Protein-Polyelectrolyte Binding Studies. In Capillary Electrophoresis of Proteins and Peptides; Strege, M. A., Lagu, A. L., Eds.; Humana Press: Totowa, NJ, 2004; pp 217-228. https://doi.org/10.1385/1-59259-798-X:217.

(51) Lounis, F. M.; Chamieh, J.; Leclercq, L.; Gonzalez, P.; Cottet, H. Modelling and Predicting the Interactions between Oppositely and Variously Charged Polyelectrolytes by Frontal Analysis Continuous Capillary Electrophoresis. Soft Matter 2016, 12 (48), 97289737. https://doi.org/10.1039/C6SM01811D.

(52) Zou, T.; Oukacine, F.; Le Saux, T.; Cottet, H. Neutral Coatings for the Study of Polycation/Multicharged Anion Interactions by Capillary Electrophoresis: Application to Dendrigraft Poly- L -Lysines with Negatively Multicharged Molecules. Anal. Chem. 2010, 82 (17), 7362-7368. https://doi.org/10.1021/ac101473g.

(53) Østergaard, J.; Khanbolouki, A.; Jensen, H.; Larsen, C. Complexation between LowMolecular-Weight Cationic Ligands and Negatively Charged Polymers as Studied by Capillary Electrophoresis Frontal Analysis. Electrophoresis 2004, 25 (1819), 3168-3175. https://doi.org/10.1002/elps.200406051.

(54) Jensen, H.; Østergaard, J.; Thomsen, A. E.; Hansen, S. H. CE Frontal Analysis Based on Simultaneous UV and Contactless Conductivity Detection: A General Setup for Studying Noncovalent Interactions. Electrophoresis 2007, 28 (3), 322-327. https://doi.org/10.1002/elps.200600365. 
(55) Gao, J. Y.; Dubin, P. L.; Muhoberac, B. B. Measurement of the Binding of Proteins to Polyelectrolytes by Frontal Analysis Continuous Capillary Electrophoresis. Anal. Chem. 1997, 69 (15), 2945-2951. https://doi.org/10.1021/ac970026h.

(56) Hattori, T.; Hallberg, R.; Dubin, P. L. Roles of Electrostatic Interaction and Polymer Structure in the Binding of $\beta$-Lactoglobulin to Anionic Polyelectrolytes: Measurement of Binding Constants by Frontal Analysis Continuous Capillary Electrophoresis. Langmuir 2000, 16 (25), 9738-9743. https://doi.org/10.1021/la000648p.

(57) Sisavath, N.; Leclercq, L.; Le Saux, T.; Oukacine, F.; Cottet, H. Study of Interactions between Oppositely Charged Dendrigraft Poly-l-Lysine and Human Serum Albumin by Continuous Frontal Analysis Capillary Electrophoresis and Fluorescence Spectroscopy. $J$. Chromatogr. A 2013, 1289, 127-132. https://doi.org/10.1016/j.chroma.2013.03.016.

(58) Sisavath, N.; Le Saux, T.; Leclercq, L.; Cottet, H. Effect of Dendrimer Generation on the Interactions between Human Serum Albumin and Dendrigraft Polylysines. Langmuir 2014, 30 (15), 4450-4457. https://doi.org/10.1021/la5002144.

(59) Cooper, C. L.; Dubin, P. L.; Kayitmazer, A. B.; Turksen, S. Polyelectrolyte-Protein Complexes. Curr. Opin. Colloid Interface Sci. 2005, 10 (1-2), 52-78. https://doi.org/10.1016/j.cocis.2005.05.007.

(60) Gao, J. Y.; Dubin, P. L.; Muhoberac, B. B. Capillary Electrophoresis and Dynamic Light Scattering Studies of Structure and Binding Characteristics of Protein-Polyelectrolyte Complexes. J. Phys. Chem. B 1998, 102 (28), 5529-5535. https://doi.org/10.1021/jp980507k.

(61) Jia, Z.; Ramstad, T.; Zhong, M. Determination of Protein-Drug Binding Constants by Pressure-Assisted Capillary Electrophoresis (PACE)/Frontal Analysis (FA). J. Pharm. Biomed. Anal. 2002, 30 (3), 405-413. https://doi.org/10.1016/S0731-7085(02)00223-6.

(62) Østergaard, J.; Heegaard, N. H. H. Capillary Electrophoresis Frontal Analysis: Principles and Applications for the Study of Drug-Plasma Protein Binding. Electrophoresis 2003, 24 (17), 2903-2913. https://doi.org/10.1002/elps.200305526.

(63) Le Saux, T.; Varenne, A.; Perreau, F.; Siret, L.; Duteil, S.; Duhau, L.; Gareil, P. Determination of the Binding Parameters for Antithrombin-Heparin Fragment Systems by Affinity and Frontal Analysis Continuous Capillary Electrophoresis. J. Chromatogr. A 2006, 1132 (1-2), 289-296. https://doi.org/10.1016/j.chroma.2006.07.092.

(64) Sun, H.; He, P. Characterization of Interaction between Doxycycline and Human Serum Albumin by Capillary Electrophoresis-Frontal Analysis. Electrophoresis 2009, 30 (11), 1991-1997. https://doi.org/10.1002/elps.200800470.

(65) Østergaard, J.; Schou, C.; Larsen, C.; Heegaard, N. H. H. Evalution of Capillary Electrophoresis-Frontal Analysis for the Study of Low Molecular Weight Drug-Human Serum Albumin Interactions. Electrophoresis 2002, 23 (17), 2842-2853. https://doi.org/10.1002/1522-2683(200209)23:17<2842::AID-ELPS2842>3.0.CO;2-B.

(66) Østergaard, J.; Schou, C.; Larsen, C.; Heegaard, N. H. H. Effect of Dextran as a Run Buffer Additive in Drug-Protein Binding Studies Using Capillary Electrophoresis Frontal Analysis. Anal. Chem. 2003, 75 (2), 207-214. https://doi.org/10.1021/ac0261146.

(67) Hattori, T.; Kimura, K.; Seyrek, E.; Dubin, P. L. Binding of Bovine Serum Albumin to Heparin Determined by Turbidimetric Titration and Frontal Analysis Continuous Capillary Electrophoresis. Anal. Biochem. 2001, 295 (2), 158-167. https://doi.org/10.1006/abio.2001.5129.

(68) Le Saux, T. Détermination Des Paramètres d'interaction Non-Covalente En Solution Par Les Méthodes Électrophorétiques Capillaires. Champ d'application et Performances. 
Rationalisation Des Protocoles, Ph.D. Dissertation, Pierre and Marie Curie University, Paris, 2004.

(69) Sisavath, N. Etude Des Interactions En Solution Par Électrophorèse Capillaire :

Application Au Cas Des Dendrimères Greffés de La Lysine, Ph.D. Dissertation, University of Montpellier, Montpellier, 2014.

(70) Lounis, F. M.; Chamieh, J.; Gonzalez, P.; Cottet, H.; Leclercq, L. Prediction of Polyelectrolyte Complex Stoichiometry for Highly Hydrophilic Polyelectrolytes.

Macromolecules 2016, 49 (10), 3881-3888. https://doi.org/10.1021/acs.macromol.6b00463.

(71) Wu, F.-G.; Jiang, Y.-W.; Sun, H.-Y.; Luo, J.-J.; Yu, Z.-W. Complexation of Lysozyme with Sodium Poly(Styrenesulfonate) via the Two-State and Non-Two-State Unfoldings of Lysozyme. J. Phys. Chem. B 2015, 119 (45), 14382-14392.

https://doi.org/10.1021/acs.jpcb.5b07277.

(72) Dubey, S.; Kalia, Y. N. Non-Invasive Iontophoretic Delivery of Enzymatically Active Ribonuclease A (13.6kDa) across Intact Porcine and Human Skins. J. Controlled Release 2010, 145 (3), 203-209. https://doi.org/10.1016/j.jconrel.2010.04.020.

(73) Łapińska, U.; Saar, K. L.; Yates, E. V.; Herling, T. W.; Müller, T.; Challa, P. K.; Dobson, C. M.; Knowles, T. P. J. Gradient-Free Determination of Isoelectric Points of Proteins on Chip. Phys. Chem. Chem. Phys. 2017, 19 (34), 23060-23067. https://doi.org/10.1039/C7CP01503H.

(74) Girardot, M. Aptamères et Électrophorèse Capillaire : Caractérisation Physico-Chimique d'aptamères Libres En Solution Ou Greffés Sur Des Nanoparticules, et Étude de Leur Affinité Avec Une Cible Protéique En Vue de Leur Emploi Pour Des Méthodes Sensibles de Diagnostic, Ph.D. Dissertation, Pierre and Marie Curie University, Paris, 2010.

(75) Seyrek, E.; Dubin, P. L.; Tribet, C.; Gamble, E. A. Ionic Strength Dependence of ProteinPolyelectrolyte Interactions. Biomacromolecules 2003, 4 (2), 273-282. https://doi.org/10.1021/bm025664a.

(76) Qin, L.; Xu, Y.; Han, H.; Liu, M.; Chen, K.; Wang, S.; Wang, J.; Xu, J.; Li, L.; Guo, X. $\beta$ Lactoglobulin (BLG) Binding to Highly Charged Cationic Polymer-Grafted Magnetic Nanoparticles: Effect of Ionic Strength. J. Colloid Interface Sci. 2015, 460, 221-229. https://doi.org/10.1016/j.jcis.2015.08.056.

(77) Wang, X.; Zheng, K.; Si, Y.; Guo, X.; Xu, Y. Protein-Polyelectrolyte Interaction: Thermodynamic Analysis Based on the Titration Method $\uparrow$. Polymers 2019, 11 (1), 82. https://doi.org/10.3390/polym11010082. 
For Table of Contents use only:

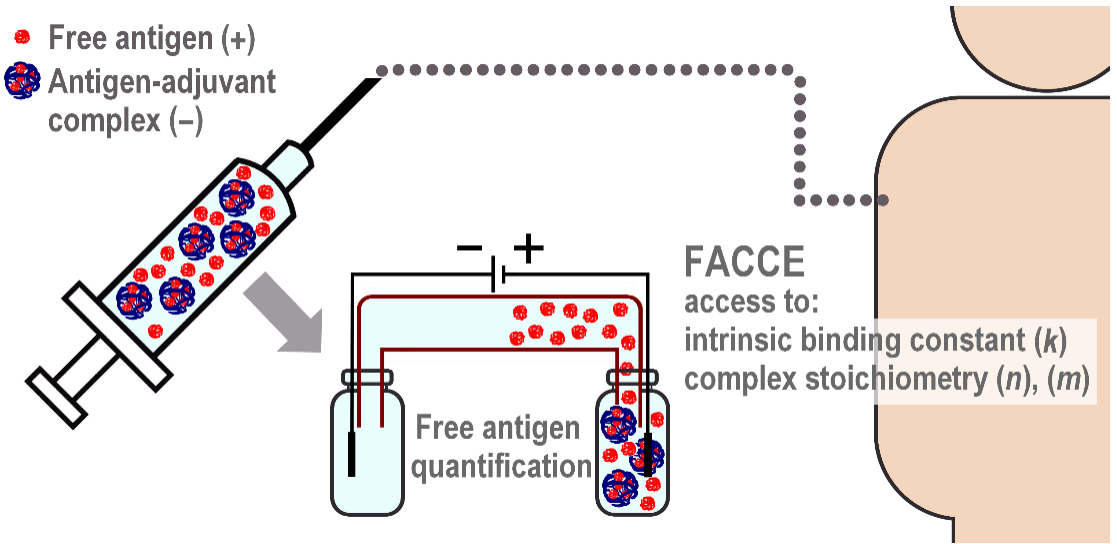

